\title{
Tell your friends: taking rumour and gossip seriously, but not literally, in biodiversity conservation
}

\author{
GEORGE HOLMES
}

Gossip and rumour must be near-universal features of conservation: every project I have worked on has featured them. My arrival at my $\mathrm{PhD}$ field site, a village bordering a small nature reserve in the Dominican Republic, prompted rumours that I was a prospector and geologist working for a secret gold mine within the reserve. Whilst studying privately protected areas in southern Chile, I regularly had respondents recall rumours, widespread during the early 1990s, that the conservation philanthropist Douglas Tompkins was using his privately protected areas as a front for some other agenda, including a CIA-sponsored coup, a sinister Zionist plot, and a plan to steal Chile's water (Holmes, 2014). During research on a rewilding project in west Wales, we encountered rumours that a lynx, escaped from a nearby zoo, had killed 5-10 sheep before being shot dead.

Everyone, it seems, enjoys a good gossip. Yet it is absent from most accounts of conservation projects. This underreporting is perhaps unsurprising, given how conservation is understood and studied by most people in the field, with the exception of anthropologists and like-minded travellers who derive data, theory, and possibly enjoyment, from a good gossip (Gluckman, 1963; Walley, 2004; Rapport, 2009). The informal, transient, dynamic nature of rumours and gossip is difficult to capture with structured methods. Like folklore and traditional beliefs, rumours are easily dismissed as untrue, unsubstantiated or unscientific. On occasion, they are used as evidence of the apparent ignorance or backwardness of gossipers, in contrast to the superior and scientific knowledge of conservationists (Skogen et al., 2008), or to discredit local opposition by portraying it as based on illogical and untrue stories (Holmes, 2014). But rumours and gossip, even when not true, do contain some indirect or distorted truths. They should not necessarily be taken literally, but they should be taken seriously.

In the examples above, the rumours are not factually true. Yet looking at the subsequent fate of each conservation initiative, it is as if they were true. Those villagers in the Dominican Republic still see the reserve as secretive, and their opposition has partly forced conservationists to change their plans (Holmes, 2013). In Chile, the political climate around Tompkins was so controversial that other owners of privately protected areas kept their distance from him, and struggled to build political support for private conservation

GEORGE Holmes (@i orcid.org/0000-0002-5393-5753, g.holmes@leeds.ac.uk) Sustainability Research Institute, University of Leeds, Leeds, UK
(Holmes, 2014). It was only after 2 decades and Tompkins' death that his vision was finally complete and his park was donated to the Chilean state. In Wales, the rewilding project has suffered significant setbacks, leading NGOs have withdrawn, and the reintroduction of large predators has been rejected (BBC News, 2018). In each case, rumours either illustrated the broader political dynamic that thwarted the projects, or had a direct impact themselves.

Anthropologists have analysed rumour as one form of the stories that people tell to make sense of their worlds. As such, rumour and gossip are best understood from the perspective of the perpetrator, rather than the observer (Gluckman, 1963). Gossip is understood as an unverified or unverifiable story, often negative, about a person or small group that is recounted outside their presence, whereas rumour is similar, but concerning an event or issue. Gossip is not idle: it has social functions and it has rules which are rigidly controlled' (Gluckman, 1963, p. 314). It creates in-groups, who know how to gossip, and who are bound together by the social act of sharing stories, and out-groups who do not and are thus excluded. Although early anthropology work on gossip and rumour explored these at village or community scale, we might also see them within the global epistemic community of conservation professionals, or in social media.

Rumours may not be factual but they reflect how the spreaders understand the world around them, and how conservation fits into this. So although I was not a gold prospector, and with no mining infrastructure visible nearby, the rumour spread because the villagers saw the reserve as backed by powerful actors, barring them from their former lands. For them, a gold mine is as good an explanation as any for why they could not access the forest. The story was not taken entirely seriously, but it circulated because it was compatible with, and reinforced, prevailing opinions (Holmes, 2013). The gossip about Tompkins spread because he had purchased land secretly through intermediaries in a politically contested territory, at a time when Chile was emerging into democracy from military rule (Holmes, 2014). It reflected deep distrust of him and his approach, and the political climate of the time.

Although the rules of rumour and gossip are specific to each culture, place and time, one curious feature of the literature on rumours in conservation is the prevalence of alternative theories of reintroductions, particularly of predators. Specifically, that government or radical environmentalists have secretly released captive-bred animals to establish or 
increase populations. Examples include wolves in Spain (Alvares et al., 2011), Norway, France (Skogen et al., 2008) and Greece (Theodorakea \& von Essen, 2016), leopards in India (Mathur, 2015), foxes and pumas in Chile (Benavides \& Caviedes, 2021), and rabbits in Spain (Delibes-Mateos, 2017). These animals have supposedly incorrect morphology, spread unnaturally quickly, are too tame or kill more frequently than native animals. The rumours may spread because they have been inspired by previous public and covert releases of key species, but also because they are salient with widely held views that these species do not belong, or are too numerous and harmful.

The early anthropology work on gossip also showed how it allowed people to informally share views that could not be aired publicly (Gluckman, 1963). Complex social negotiations could be undertaken indirectly through the medium of gossip, all whilst maintaining an outward public facade of non-interaction. In my fieldwork in the Dominican Republic, villagers who needed to avoid direct conflict to maintain social capital would resolve disputes via gossip, sending story and counter-story, peace offer and counteroffer, via village street corners and other venues.

This idea of gossip as hidden transcript shows its political potential, as it allows relatively weak groups to spread scandal about more powerful groups. The subaltern studies approach emphasized the group and personal politics of rumour and gossip, one weapon in the armoury of seemingly weak and marginalized people (Scott, 1985). Spreading rumours about a person or organization can discredit them, hinder their social interactions and undermine their purpose. For instance, rumours that wolves were being secretly released in Iberia antagonized local residents, restricting conservation officials' work and advocacy for wolves (Álvares et al., 2011). It also positioned wolves as the property and responsibility of the state. Claims in the Dominican Republic about secret goldmines were part of wider struggles over the moral obligations of conservationists towards local people and who should own and benefit from the forest's resources (Holmes, 2013). In Mafia Island Marine Park, Tanzania, where communication between conservationists and local people was poor, local people relied on rumour and gossip to understand changes in the Park, and to contest alleged abuses and malpractice (Walley, 2004). Rumour can also aid conservation: rumours that an international NGO working in Madagascar had a private jail increased their ability to influence local people (Sommerville et al., 2010), though the authors did not record whether the NGO encouraged the spread of such rumours. Rumours are free and easy to create, spread rapidly, and their origins are difficult to identify, thus allowing their creators to avoid blame (Scott, 1985). Conservationists often have substantial symbolic and political capital from scientific publications, and access to politicians and the media, but local opponents may not, so they turn to gossip to state their case. (Skogen et al., 2008). Rumouras-power-struggle is not just confined to local scales. For example, discussions of trophy hunting in social media, particularly from anonymous accounts, allow participants to spread stories that, whether true or not, can undermine the reputation and arguments of opponents.

Conservationists should take rumours and gossip seriously, because they both reflect and form part of the politics of conservation. They should attune themselves to rumour and gossip, listen for them, and learn to interpret them within the local context. Of course, rumours also spread and evolve because of the sheer joy and guilty pleasure of sharing a story. Gossiping is not just political, it is also fun, and understanding the serious and trivial performances in rumour requires understanding the local rules and context of gossip. Rumours should be taken seriously, but not too seriously. Tell your friends.

\section{References}

Álvares, F., Domingues, J., Sierra, P. \& Primavera, P. (2011) Cultural dimension of wolves in the Iberian Peninsula: implications of ethnozoology in conservation biology. Innovation: The European Journal of Social Science Research, 24, 313-331.

Benavides, P. \& Caviedes, J. (2021) Unnatural pumas and domestic foxes: relations with protected predators and conspiratorial rumours in southern Chile. Environmental Values, published online 26 May 2021.

BBC News (2018) Wildlife scheme: farmers' worries cause charity exit. BBC News, 21 October 2019. bbc.co.uk/news/uk-wales-50117566 [accessed 3 November 2021].

Delibes-Mateos, M. (2017) Rumours about wildlife pest introductions: European rabbits in Spain. Ambio, 46, 237-249.

Gluckman, M. (1963) Gossip and scandal. Current Anthropology, 4, 307-316.

Holmes, G. (2013) Exploring the relationship between local support and the success of protected areas. Conservation and Society, 11, 72-82.

Holmes, G. (2014) What is a land grab? Exploring green grabs, conservation, and private protected areas in southern Chile. Journal of Peasant Studies, 41, 547-567.

Mathur, N. (2015) "It's a conspiracy theory and climate change" Of beastly encounters and cervine disappearances in Himalayan India. HAU: Journal of Ethnographic Theory, 5, 87-111.

Rapport, N. (2009) Gossip. In The Routledge Encyclopaedia of Social and Cultural Anthropology (eds A. Barnard. \& J. Spencer), p. 337-338. Routledge, London, UK.

Scott, J.C. (1985) Weapons of the Weak: Everyday Forms of Peasant Resistance. Yale University Press, New Haven, USA.

Skogen, K., Mauz, I. \& Krange, O. (2008) Cry wolf! Narratives of wolf recovery in France and Norway. Rural Sociology, 73, 105-133.

Sommerville, M., Milner-Gulland, E.J., Rahajaharison, M. \& Jones, J.P. (2010) Impact of a community-based payment for environmental services intervention on forest use in Menabe, Madagascar. Conservation Biology, 24, 1488-1498.

Theodorakea, I.T. \& von Essen, E. (2016) Who let the wolves out? Narratives, rumors and social representations of the wolf in Greece. Environmental Sociology, 2, 29-40.

Walley, C.J. (2004) Rough Waters. Princeton University Press, Princeton, USA. 